\title{
Specific Energy Consumption in Convective-microwave Drying of Ashwagandha (Withania Somnifera) Roots
}

Ashok K Senapati ${ }^{1}$, Rao PS ${ }^{2}$, Lalit M Bal ${ }^{3^{*}}$ and Suresh Prasad ${ }^{4}$

${ }^{1}$ Department of Post-harvest Technology and Process Engineering, Navsari Agricultural University, Navsari, Gujarat - 396450, India

${ }^{2}$ Agricultural and Food Engineering, Indian Institute of Technology, Kharagpur-721302, India

${ }^{3}$ Post Harvest Process and Food Engineering, College of Agriculture, Jawaharlal Nehru Agricultural University, Tikamgarh, Madhya Pradesh- 472001, India

${ }^{4}$ Chemical and Biochemical Engineering, Indian Institute of Technology, Patna- 800013, India

\begin{abstract}
Evaluation of specific energy consumption was carried out during convective-microwave and convective drying of Ashwagandha root in a developed laboratory scale microwave dryer. The specific energy consumption in convective drying at $60^{\circ} \mathrm{C}$ of air temperature and $1.0 \mathrm{~m} / \mathrm{s}$ air velocity was estimated as $2.27 \pm 0.12$ ) MJ/kg of water evaporated. The increase in air velocity increased the energy consumption. The specific energy consumption at $6 \mathrm{~W} / \mathrm{g}$ of microwave power level, $60^{\circ} \mathrm{C}$ air temperature and $1.0 \mathrm{~m} / \mathrm{s}$ air velocity was $0.396 \pm 0.047) \mathrm{MJ} / \mathrm{kg}$ of water evaporated, resulting in about $82 \%$ energy saving as compared to convective drying processes. The drying time increased with increase in air velocity in convective - microwave drying process as a reverse trend that was observed in convective drying process of Ashwagandha roots.
\end{abstract}

Keywords: Convective drying; Convective-microwave drying; Drying time; Specific energy consumption

\section{Introduction}

The interest in medicinal plant products has been increased significantly in recent years. According to WHO survey, about $80 \%$ of the world population still relies on mainly traditional remedies such as on herbs for their primary health care needs [1]. Ashwagandha (Withania somnifera) is an important medicinal plant, widely ed as home remedy for several diseases in India as well as other parts of the world. Ashwagandha is also described as an herbal tonic and health food in Vedas and considered as Indian Ginseng in traditional Indian system of medicine. In ashwagandha plant, the root parts contain more active ingredients, volatile oil, flavour and alkaloids and withanaloids as compared to the other parts of the plants [2]. It contains nicotine and group of alkaloids and also contains the ingredients i.e. foreign matter (not more than $2 \%$ ), total ash (7\%), acid soluble ash (1\%), alkaloids (2.5\%) and water (80\%) [3]. This plant is used as a number of medicinal preparations such as ashwagandha roots powder pills and ashwagandha oil pills etc. which are commercially available in the market. Medicinal action of dried ashwagandha roots are tumors, inflammation (including arthritis), anemia, breathing difficulties, cancer, cough, insomnia, paralysis, ulcers, memory loss, women's health, skin disease, eyesight, pains and a wide range of infectious diseases.

Ashwagandha has a great export-potential in dried form, however, because of costs processing is very high in India and also the quality of the final product does not maintain to internal standards. The ashwagandha dehydration needs to be done by a technique which takes short time and maintains good quality. Drying is one of the oldest and most widely used methods of food preservations and the most effective means of preserving foods from spoilage because of longer shelf life, product diversity, vital influence on the products quality and substantial volume reduction of dried products. In India, ashwagandha roots are dried by small scale industries using by hot air drying or sun drying on the open field without any aseptic conditions and more time consuming and does not maintain the quality of the final products. Ashwagandha root has a short shelf life due to higher moisture content of about 85\% (w.b.). Application artificial drying can be significantly reduced the mould and bacteria growth as well as losses of active ingredients and post-harvest infection. But, major disadvantages of hot air drying are low energy efficiency, undesirable changes in quality of the dried products and long drying time is about $9-10 \mathrm{~h}$ at higher temperature of $60^{\circ} \mathrm{C}$ during the falling rate period [4]. Prolonged exposure of the product to elevated drying air temperature results in substantial degradation in the quality of the dried product such as colour parameters, rehydration ratio and alkaloid contents.

In recent years, microwave drying has been popularly used as drying method for a number of food products such as fruits, vegetables, snack foods and dairy products, etc. Microwaves drying is relatively a new addition in the existing drying technique viz. hot air, cabinet, spray, vacuum and freeze drying [5-7]. Microwaves are rarely used alone but rather in combination with hot air, steam, vacuum conditions or the conventional methods and the effects of the combinations are more synergistic [8]. Microwaves are electromagnetic waves in the frequency range of $300 \mathrm{MHz}$ to $300 \mathrm{GHz}$, generated by a magnetron type vacuum tube [9]. Two narrow band of microwave allotted for use in industrial food processing application are 915 and $2450 \mathrm{MHz}$ which can be absorbed by water containing materials and converted to heat [10]. Waves can penetrate directly into the material; heating is volumetric (from the inside to outside) and provides fast and uniform heating throughout the product. The quick energy absorption by water molecules causes rapid evaporation of water creating an outward flux of rapid escaping vapour. Microwaves penetrate the food from all direction which facilitates steam escape and speed heating. In addition to improve the rate of drying, this outward flux can help prevent the shrinkage of tissue structure, which prevails in most conventional air

*Corresponding author: Lalit M Bal, Post-Harvest Process and Food Engineering College of Agriculture, Jawaharlal Nehru Agricultural University, Tikamgarh, Madhya Pradesh- 472001, India, Tel: 912637-282145; E-mail: lalit.bal@gmail.com

Received May 04, 2014; Accepted August 26, 2014; Published September 03 2014

Citation: Senapati AK, Rao PS, Bal LM, Prasad S (2014) Specific Energy Consumption in Convective-microwave Drying of Ashwagandha (Withania Somnifera) Roots. J Food Process Technol 5: 362. doi:10.4172/2157-7110.1000362

Copyright: () 2014 Senapati AK, et al. This is an open-access article distributed under the terms of the Creative Commons Attribution License, which permits unrestricted use, distribution, and reproduction in any medium, provided the original author and source are credited. 
drying technique. Hence, better rehydration characteristics may be expected in microwave dried products [5]. Microwave processes offer a lot of advantages such as less start up time, faster heating, energy efficiency (most of the electromagnetic energy is converted to heat), space savings, precise process control and food product with better nutritional quality.

Most research work on combined microwave- convective drying of agricultural commodities has been reported for low moisture food products [11-15]. But, ashwagandha root is a high moisture commodity and having medicinal value, it requires mild heat for shorter period drying. So, the development of convective - microwave drying that reduces the drying time and produces good quality of ashwagandha roots. However, very less work has been undertaken in India under hot air drying of medicinal roots and no work reported on the convective - microwave drying of medicinal ashwagandha roots. Keeping in this view, the present investigation was aimed to study the specific energy consumption aspects in convective- microwave as well as convective drying processes of ashwagandha roots.

\section{Materials and Methods}

Fresh ashwagandha (W. somnifera) roots were procured from medicinal farm, Kharagpur and stored in a cold storage chamber (5 $\left.\pm 1^{\circ} \mathrm{C}, 85 \% \mathrm{RH}\right)$ for further analysis. The initial moisture content of ashwagandha root measured was 4.5-5.0 g water/g dry matter.

\section{Moisture content}

The vacuum oven method was used to determine the moisture content of ashwagandha root. The roots samples of approximately 30 $\mathrm{g}$ were placed in a pre-dried aluminum dishes in vacuum oven. The operating temperature was taken as that of $70^{\circ} \mathrm{C}$ at negative pressure of $13.3 \mathrm{kPa}$ and the sample was taken out of oven after $24 \mathrm{~h} \mathrm{[16].} \mathrm{The}$ samples were cooled in desiccator and weighed using an ANAMED top pan electric balance with a sensitivity of $0.01 \mathrm{~g}$. The fresh and bone dried roots weights were taken to calculate the moisture content expressed as g water/g dry matter [17].

\section{Experimental procedure}

Ashwagandha root were taken out from cold storage and allowed to equilibrate with ambient conditions. Roots were washed thoroughly and cut into $5 \mathrm{~cm}$ length under the hygienic conditions. Then the samples were pre-treated with hot water at $100^{\circ} \mathrm{C}$ for $2 \mathrm{~min}$ to improve the quality of the dehydrated product. A sample of about $100 \mathrm{~g}$ of roots was used for drying experiments.

A $900 \mathrm{~W}, 2450 \mathrm{MHz}$ microwave oven (IFB make, model Electron) having inside chamber dimension of 300 (width) $\times 240$ (depth) $\times 210$ (height) $\mathrm{mm}^{3}$ was used for the experiment $[18,19]$. The oven had the facility to adjust power supply and the time of processing. A variac of $15 \mathrm{~A} / 230 \mathrm{~V}$ rating was also placed on the primary side of the high voltage transformer to regulate the anode current, thus varying the output power of the magnetron between 0 and $600 \mathrm{~W}$ with 5 duty cycles or settings. Calibration of microwave output power level was done using IMPI-2L test [20,21]. A small air blower of $2.5 \mathrm{~m}^{3} / \mathrm{min}$ capacity and electric heater of $2 \mathrm{~kW}$ power was used to supply hot air in the experimental dryer. The hot air was sucked by the blower through the heaters and was thrown into the drying chamber. These chambers had a screen at the bottom with an approximately $1 \mathrm{~mm}$ diameter hole. The temperatures were measured by thermometer, whereas air velocity was measured by an anemometer (Make: Kanomax, Japan) with 0.1 $\mathrm{m} / \mathrm{s}$ least count.
The dryer was run idle for about $30 \mathrm{~min}$ to set the desired drying conditions before each drying experiments. The convective drying experiment on ashwagandha roots was carried out at drying air temperature of 40,50 and $60^{\circ} \mathrm{C}$, air velocities of 1.0 and $1.5 \mathrm{~m} / \mathrm{s}$. The convective-microwave drying experiments were carried out at different microwave power levels of 2,4 and $6 \mathrm{~W} / \mathrm{g}$, at air velocities of 1.0 and 1.5 $\mathrm{m} / \mathrm{s}$ and air temperatures of 40,50 and $60^{\circ} \mathrm{C}$. The samples were placed inside the microwave cavity. The drying was performed according to the preset power and time schedule, placing samples inside the microwave cavity. The weight loss of the roots was determined after every 1-5 min until it reached to a moisture content of about $0.6 \mathrm{~g}$ water/g dry matter. Three replications were taken for each experiment to get an average value.

\section{Specific energy consumption in drying process}

The drying of food material, a process of simultaneous heat and mass transfer, is energy intensive operation of industrial significance. The specific energy consumption was estimated, both in convective drying and convective -microwave drying process, considering the total energy required to dry ashwagandha roots from initial moisture content of $5.06 \mathrm{~kg}$ water $/ \mathrm{kg}$ of dry matter to final moisture content of $0.06 \mathrm{~kg}$ water $/ \mathrm{kg}$ of dry matter. Heat lost through exhaust air has not been taken into consideration, for the reason that there was no heat recovery during drying process. The specific energy consumption, E, was expressed as follows:

$$
\mathrm{E}=\frac{\text { Total energy supplied in drying process }}{\text { Amount of water removed during drying }}, \mathrm{kJ} / \mathrm{kg}
$$

Enthalpy of the drying air was estimated from its psychometric properties. The energy requirement of air was worked out, assuming the efficiency of the electrical heater (of capacity $1.5 \mathrm{~kW}$ ) to be $90 \%$. An air blower of $210 \mathrm{~W}$ was used in the experimental dryer and its overall efficiency was assumed to be $70 \%$. A $3.5 \mathrm{~W}$ motor was used to rotate the sample and its efficiency was assumed to be $90 \%$. The microwave systems (Magnetrons) are only 50\% efficient in converting the line power to microwave power [22]. It was therefore assumed that actual power consumed is double the applied microwave power, for energy usage computation purpose $[17,23]$. Specific energy consumption in convective drying process $E_{c}$ is as follows:

$E_{c}=\frac{E_{1}+E_{2}}{W_{e}}, \mathrm{~kJ} / \mathrm{kg}$ of moisture removed

and, specific energy consumption in convective-microwave drying process, $E_{m w}$ is as follows:

$E_{m w}=\frac{E_{1}+E_{2}+E_{3}+E_{4}}{W_{e}} \mathrm{~kJ} / \mathrm{kg}$ moisture removed

Where $\mathrm{E}_{1}=$ =energy required to heat the air, $\mathrm{kJ} ; \mathrm{E}_{2}=$ =nergy requirement of the air blower, $\mathrm{kJ} ; \mathrm{E}_{3}=$ energy requirement of the magnetron, $\mathrm{kJ}$; $\mathrm{E}_{4}$ =energy requirement for rotating the food sample inside the drier, $\mathrm{kJ} ; \mathrm{W}_{\mathrm{e}}=$ amount of moisture removed during the drying process, $\mathrm{kg}$.

This convective and convective-microwave drying of ashwagandha roots was accomplished in the same drying unit, results hold good for a relative comparison of the process in respect of specific energy consumption.

\section{Statistical analyses}

The results obtained were subjected to analysis of variance (ANOVA) using SPSS 10.0 software. The means obtained from each set were compared using the Duncan's multiple range test based on a complete randomized design (at 0.05 confidence level). 


\section{Results and Discussion}

The drying times involved in reducing the moisture content of ashwagandha roots from initial moisture content of $5.06 \mathrm{~kg}$ water/ $\mathrm{kg}$ of dry matter to final moisture content of $0.06 \mathrm{~kg}$ water $/ \mathrm{kg}$ of dry matter, under various convective and convective-microwave drying conditions, are presented in Table 1 . These drying time values were used in estimating the specific energy consumption in the drying process. Specific energy consumption under convective drying condition was estimated, using Equation (2) and presented in Figure 1. It is evident from Figure 1 that as temperature of drying air was increased from 40 $-60^{\circ} \mathrm{C}$, the specific energy consumption decreased from $2.43 \pm 0.15$ $2.27 \pm 0.12 \mathrm{MJ} / \mathrm{kg}$ of water evaporated at an air velocity of $1.0 \mathrm{~m} / \mathrm{s}$. This was because of the dramatic reduction in the drying time with increase in air temperature. A similar trend was also observed in the specific energy consumption at air velocity of $1.5 \mathrm{~m} / \mathrm{s}$. At a given air temperature, specific energy consumption was found to be higher at higher velocity during the convective drying process, for the reason that higher air velocity did not reduce the drying time appreciably as moisture transport within the material being controlled by diffusion process [24]. Motevali et al. [25] reported that the values of specific energy consumption increases with increase in air velocity for each temperature level. They also found that specific energy consumption decreased as temperature increased at constant air velocity. With increasing temperature, the drying time was reduced due to increased thermal gradients inside the material that, consequently, increased the product drying rate (Figure 2).

The specific energy consumption for the convective - microwave drying of ashwagandha roots under different drying temperatures i.e. 40,50 and $60^{\circ} \mathrm{C}$ was estimated from Equation (3) for power levels of 2,4 and $6 \mathrm{~W} / \mathrm{g}$ at air velocities 1.0 and $1.5 \mathrm{~m} / \mathrm{s}$ are shown in Figure 3. The specific energy consumption reduced drastically during the convective - microwave process as compared to the convective drying process. Energy consumption at $6 \mathrm{~W} / \mathrm{g}$ microwave power output, 60 ${ }^{\circ} \mathrm{C}$ air temperature, and 1.0 and $1.5 \mathrm{~m} / \mathrm{s}$ air velocities was $0.396 \pm 0.047$ and $0.436 \pm 0.057 \mathrm{MJ} / \mathrm{kg}$ of water removed, which was about $82 \%$ of the energy consumption in convective drying under similar drying conditions. This reduction in energy consumption was because of the volumetric heating effect by microwaves, which reduced the drying time [17]. Considerably, a similar reduction in the energy consumption was observed in other convective - microwave drying conditions also, compared to convective drying [26]. It was also observed

\begin{tabular}{|c|c|c|c|}
\hline \multirow{2}{*}{$\begin{array}{l}\text { Microwave power } \\
\text { level }(W / g)\end{array}$} & \multirow{2}{*}{$\begin{array}{l}\text { Air temperature } \\
\left({ }^{\circ} \mathrm{C}\right)\end{array}$} & \multicolumn{2}{|l|}{ Drying time (h) } \\
\hline & & $\begin{array}{l}\text { Air velocity } 1.0 \\
\mathrm{~m} / \mathrm{s}\end{array}$ & $\begin{array}{l}\text { Air velocity } 1.5 \\
\mathrm{~m} / \mathrm{s}\end{array}$ \\
\hline 0 & 40 & 9.5 & 8.5 \\
\hline 0 & 50 & 8.3 & 7.5 \\
\hline 0 & 60 & 8.0 & 7.0 \\
\hline 2 & 40 & 1.250 & 1.343 \\
\hline 2 & 50 & 1.116 & 1.250 \\
\hline 2 & 60 & 1.081 & 1.166 \\
\hline 4 & 40 & 1.083 & 1.166 \\
\hline 4 & 50 & 1.00 & 1.082 \\
\hline 4 & 60 & 0.916 & 1.00 \\
\hline 6 & 40 & 0.917 & 1.00 \\
\hline 6 & 50 & 0.835 & 0.917 \\
\hline 6 & 60 & 0.750 & 0.833 \\
\hline
\end{tabular}

Table 1: Drying time for convective and convective - microwave drying conditions of Ashwagandha roots
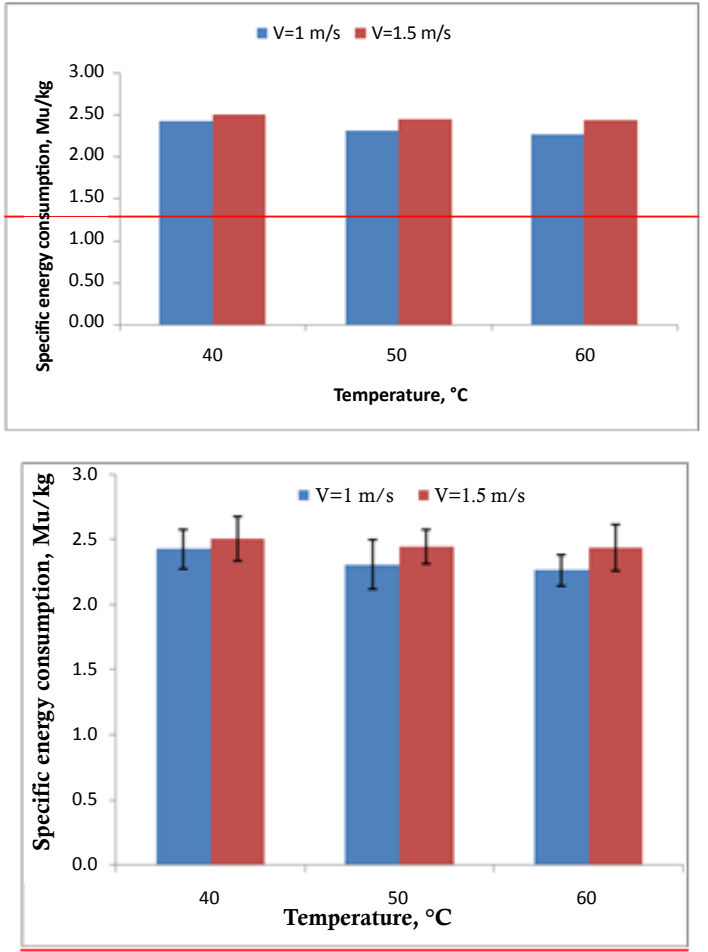

Figure 1: Specific energy consumption in different conditions for convective drying of Ashwagandha roots.
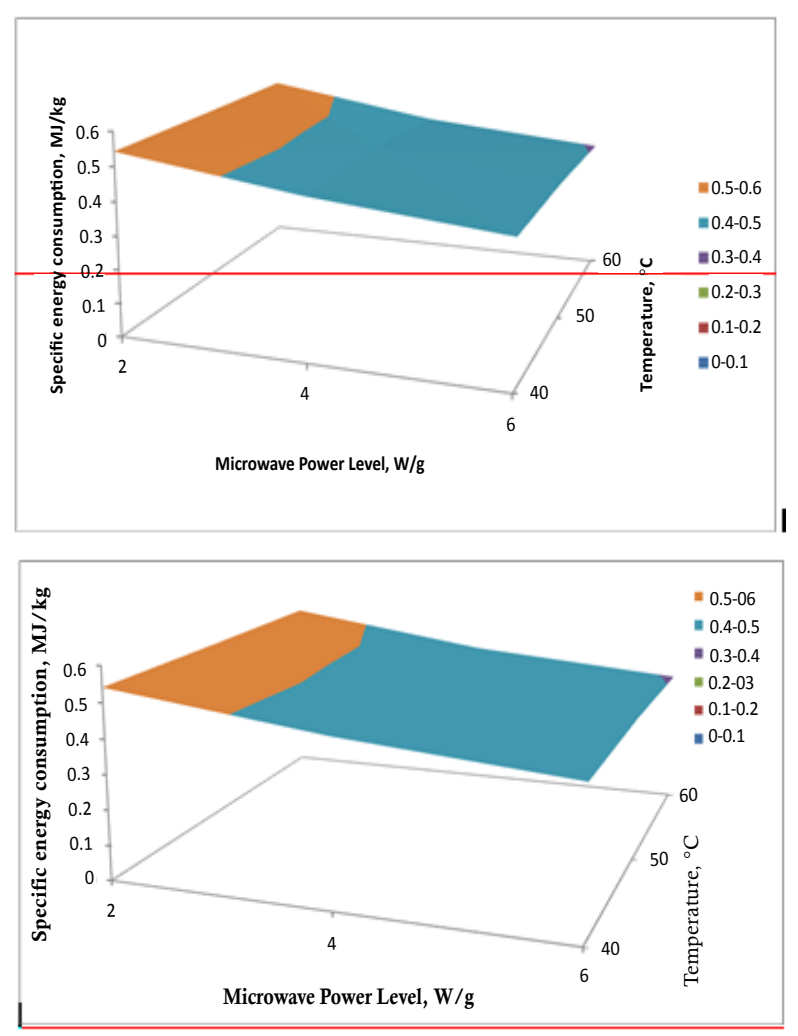

Figure 2: Variation in specific energy consumption for convective Microwave drying of Ashwagandha roots at air velocity of $1.0 \mathrm{~m} / \mathrm{s}$. 

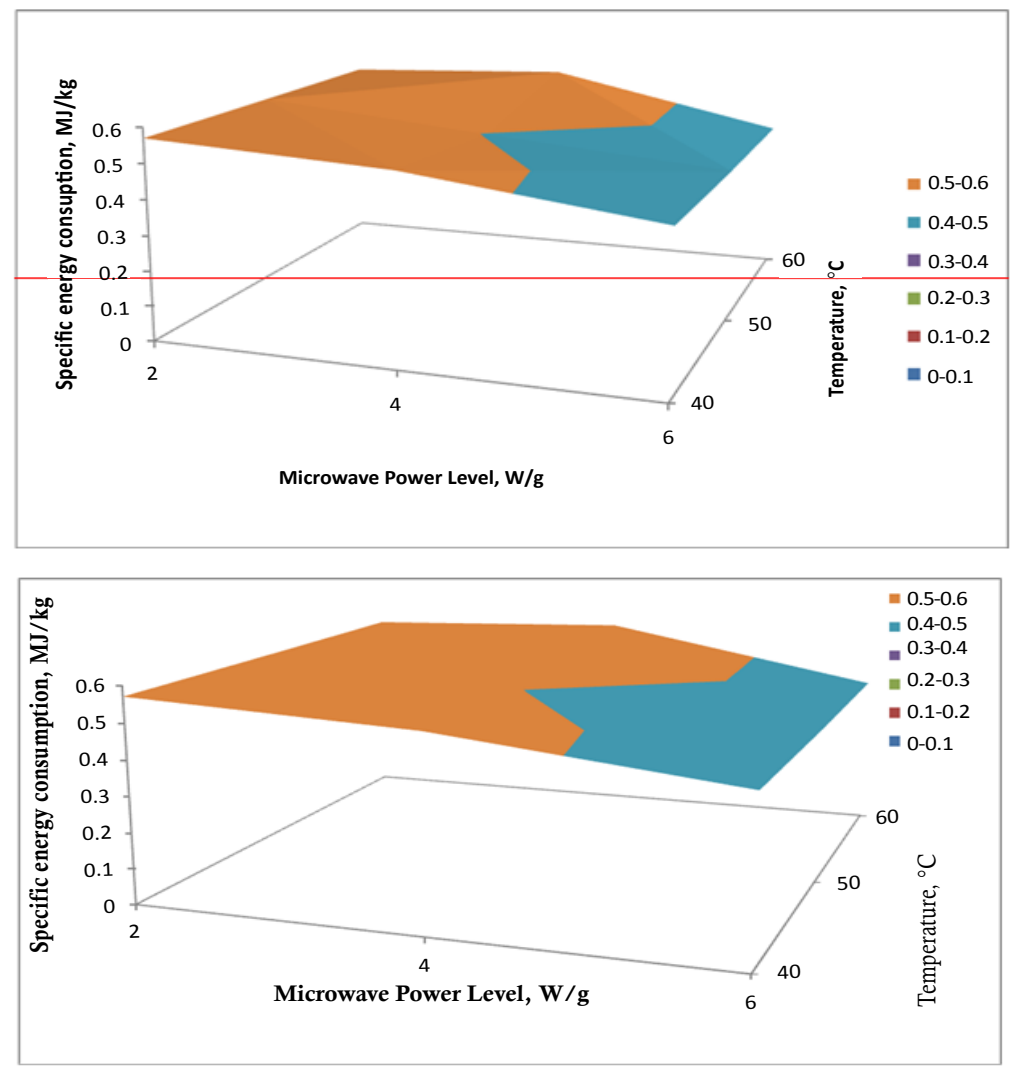

Figure 3: Variation in specific energy consumption for convective - Microwave drying of Ashwagandha roots at air velocity of $1.5 \mathrm{~m} / \mathrm{s}$

under convective -microwave drying process that as air velocity was increased from 1.0 to $1.5 \mathrm{~m} / \mathrm{s}$ at a given air temperature, specific energy consumption also increased. This was because the increase in air velocity resulted in cooling of drying product, i.e. reducing its temperature and thus increasing the drying time. Several other researchers $[10,12]$ have also reported similar findings. Since convective and convectivemicrowave drying of ashwagandha roots was carried out in the same dryer; this relative comparison of specific energy appears to be valid.

\section{Conclusions}

It was observed that specific energy consumption diminished when temperature increased at each air velocity, while it increased with increasing hot air velocity. The convective drying process is very energy intensive and results in deleterious effects on the quality of the product. The convective-microwave drying of ashwagandha roots was found to be about 9-10 times faster than convective drying. The specific energy consumption in the microwave-convective drying process could be as low as $82 \%$ as compared to the convective drying process. This process has also tremendous potential for the processing of other agricultural produces.

\section{References}

1. Farnsworth NR, Akerele O, Bingel AS, Soejarto DD, Guo Z (1985) Medicinal plants in therapy. B World Health Organ 63: 965-981.

2. Singh G, Sharma PK, Dudhe R, Singh S (2010) Biological activities of Withania somnifera. Ann Biol Res 1: 56-63.

3. Baraiya BR, Tiwari G, Sonakia VK. (2004) Alkaloid concentration in different parts of growing crop of Ashwagandha (Withania somtrifera) at different growth intervals. Jabalpur: Department of Plant Physiology, JNKVV.
4. Madamba PS, Driscoll RH, Buckle KA (1996) The thin layer drying characteristic of garlic slices. J Food Eng 29: 75-97.

5. Prabhanjan DG, Ramaswamy HS, Raghavan GSV (1995) Microwave-assisted convective air drying of thin layer carrots. J Food Eng 25: 283-293.

6. Ren G, Chen F (1998) Drying of american ginseng (Panax quinquefolium) roots by microwave-hot air combination. J Food Eng 35: 433-443.

7. Bal LM, Kar A, Satya S, Naik SN (2010) Drying kinetics and effective moisture diffusivity of bamboo shoot slices undergoing microwave drying. Int J Food Sci Technol 45: 2321-2328.

8. Khraisheh MAM, McMinn WAM, Magee TRA (1999) A multiple regression approach to the combine microwave and air drying process. J Food Eng 43: 243-250.

9. Schiffmann RF (1992) Microwave processing in the US food industry. Food Technol 50: 52-56.

10. Khraisheh MAM, Cooper TJR, Magee TRA (1997) Investigation and modeling of combined microwave and air drying. Trans Inst Chem Eng 73: 121-126.

11. Maskan M (2000) Microwave/air and microwave finish drying of banana. J Food Eng 44: $71-75$.

12. Tulasidas TN, Raghavan GSV, Norris ER (1993) Microwave and convective drying of grapes. Trans ASAE 36(6): 1861-1865.

13. Maskan M (2001) Drying, shrinkage and rehydration characteristics of kiwifruit during hot air and microwave drying. J Food Eng 48: 177-182.

14. Swain S, Samuel DVK, Bal LM, Kar A, Sahoo GP (2012) Modeling the microwave assisted drying process of osmotically pretreated red sweet pepper (Capsicum annum L.). Food Sci Biotech 21: 969-978.

15. Swain S, Samuel DVK, Bal LM, Kar A (2014) Thermal kinetics of colour degradation of yellow sweet pepper (Capsicum annum L.) undergoing microwave assisted convective drying. Int J Food Prop 17: 1946-1964. 
Citation: Senapati AK, Rao PS, Bal LM, Prasad S (2014) Specific Energy Consumption in Convective-microwave Drying of Ashwagandha (Withania Somnifera) Roots. J Food Process Technol 5: 362. doi:10.4172/2157-7110.1000362

Page 5 of 5

16. Young G, Mason R (2002) Evaluation of various pre-treatments for the dehydration of banana and selection of suitable drying models. J Food Eng 55: $139-146$

17. Sharma GP, Prasad S (2006) Specific energy consumption in microwave drying of garlic cloves. Energy 31: 1921-1926.

18. Tong $\mathrm{CH}$, Lentz RR, Lund DB (1993) A microwave oven with variable continuous power and a feedback temperature controller. Biotechnol Prog 9: 488-496.

19. Sharma GP, Prasad S (2001) Drying of garlic (Allium sativum) cloves by microwave-hot air combination. J Food Eng 50: 99-105.

20. Buffler CR (1993) Microwave cooking and processing: Engineering fundamentals for the food scientist. New York: Van Nostrand Reinhold.
21. Bal LM, Kar A, Satya S, Naik SN (2011) Kinetics of color change of bamboo shoot during microwave drying. Int J Food Sci Technol 46: 827-833.

22. Metaxas AC, Meretith RJ (1983) Industrial microwave heating. England: Peter Peregrinus Ltd.

23. Motevali A, Minaei S, Khoshtagaza MH (2011) Evaluation of energy consumption in different drying methods. Energy Con Manag 52: 1192-1199.

24. Sharma GP, Prasad S (2005) Effective moisture diffusivity of garlic cloves undergoing microwave-convective drying. J Food Eng 65: 609-617.

25. Motevali A, Abbaszadeh A, Minaei S, Khoshtaghaza MH, Ghobadian B (2012) Effective moisture diffusivity, activation energy and energy consumption in thinlayer drying of jujube (Zizyphus jujube Mill). J Agr Sci Tech 14: 523-532.

26. Lyons DW, Hatcher JD, Sunderland JE (1972) Drying of porous medium with internal heat generation. Int J Heat Mass Transfer 15: 897-904. 